Review

\title{
Observational Pilot Study: A comparison of Amino Acids and Derangement of Intestinal Absorption between Healthy Age- ing Subjects and Patients Affected by Chronic Kidney Disease in Conservative Management
}

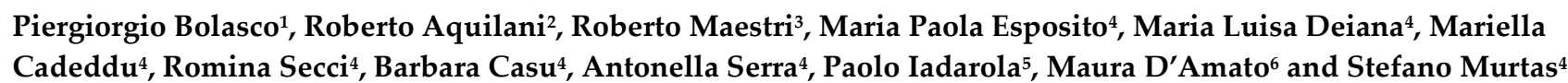

${ }^{1}$ Chronic Kidney Disease Treatment Conservative Study Group of the Italian Society of Nephrology, Rome Italy. https://orcid.org/ 0000-0001-9788-2342;

2 Department of Biology and Biotechnology "Lazzaro Spallanzani”, University of Pavia, Italy;

3 Department of Biomedical Engineering of the Montescano Institute, Scientific Clinic Institute

Maugeri IRCCS, 27040 Montescano, Italy;

${ }^{4}$ ASSL of Cagliari, Sardinia, Italy

5

5 Department of Biology and Biotechnologies “L. Spallanzani”, University of Pavia, 27100 Pavia, Italy

6 Department of Molecular Medicine University of Pavia, Pavia, Italy

* Correspondence: Author: Piergiorgio Bolasco, M.D., Via Albert Einstein, 21, 09126 Cagliari - Italy; pg.bolasco@gmail.com; Phone: +39 070 308619; Fax +39 0706097340

\begin{abstract}
Background: A comparison of the aminoacid (AA) plasma profile and markers of intestinal absorption-inflammation between healthy subjects aged 65-70 years and age-matched patients affected by stage $3 b-4$ chronic kidney disease (CKD3b-4) was performed. Methods: eleven healthy volunteers were compared with 12 CKD3b-4 patients at the their first outpatient control (T0) and after 12-months (T12). Adherence to a low protein diet (LPD, $0.6 \pm 0.1 \mathrm{~g} / \mathrm{kg} /$ day) was assessed by Urea Nitrogen Appearance. The following parameters were assessed: renal function, nutritional parameters, bioelectrical impedance analysis, plasma levels of 20 total aminoacids (TAAs), both essential (EAAs) including branched-chain amino acids (BCAAs) and non-essential (NEAAs). Zonulin and faecal Calprotectin markers were used to evaluate intestinal permeability/inflammation. Results: Four patients dropped out of the study; in the remaining 8 residual kidney function (RKF) remained stable, their LPD adherence had risen to $0.89 \mathrm{~g} / \mathrm{kg} / \mathrm{day}$, anaemia had worsened and extracellular body fluid had increased. In comparison to healthy subjects, TAA levels of histidine, arginine, asparagine, threonine, glycine, and glutamine had all increased. No variation in BCAAs was observed. A significant increase was detected in faecal calprotectin and zonulin levels in CKD patients as the disease progressed. Conclusions: This study confirms the finding in aged patients of an alteration in levels of several AAs secondary to uraemia. Intestinal markers provide confirmation of a relevant alteration to the intestinal function in CKD patients.
\end{abstract}

Keywords: Chronic Kidney Disease, aminoacids, Dysbiosis, metabolic disorders.

\section{Introduction}

The study of alterations to the amino acid (AA) metabolism in conservatively managed chronic kidney disease (CKD) [1-4] has recently been the focus of renewed interest. CKD features evolutionary potential despite the implementation of therapeutic and nutritional procedures; an understanding of AA kinetics and metabolism may 
contribute towards a better perception and optimised conservation of a good nutritional status, whilst at the same time attempting to slow down the progression of CKD [5-6]. Other fundamental measures to be employed are focused on preserving key functions of the microbiota affected by the onset of uraemia and by changes in absorption of the intestinal wall underlying a further rise in toxicity of the uremic setting [7-8]. To date however, literature reports relating to the effect of AA metabolism and kinetics on CKD progression have failed to produce validated findings. Likewise, the effect elicited by a direct action of the amino acid profile and metabolism in CKD on intestinal function and uremic microbiota remains to be clarified, although it is undoubtedly conditioned by a reduction of protein dietary intake [9]. It should be highlighted how, at the current stateof-the-art, patient populations aged 65 years and over affected by mild-moderate CKD display a 20-25\% prevalence of Protein Energy Wasting (PEW), which gradually increases to $30-40 \%$ in the more severe forms of CKD. The most widely acknowledged causes include: CKD-induced protein hypercatabolism with loss of muscle mass, reduced amino acid intake, loss of appetite, reduced physical exercise and a range of depressive syndromes [10-11]. Literature reports relating to the study of AA plasma levels in healthy elderly subjects or elderly CKD patients at various stages are somewhat lacking and illdefined. Greater attention should focus on the higher percentage of nephrology outpatients over the age of 65-70 years affected by CKD stages $3 \mathrm{~b}$ and 4 [12]. Indeed, even ten years ago, the percentage of conservatively managed stage $3 b-4$ CKD patients over the age of 65 years exceeded $80 \%$ [13], and as they age, these patients become increasingly fragile and vulnerable and undergo uraemia-induced changes to the protein-metabolism and intestinal function. Moreover, in healthy elderly subjects, more coherent ranges should be taken into account in establishing age-adjusted values compared to the traditional K-DIGO criteria [12], particularly as values for estimated Glomerular Filtration Rate (eGFR) should routinely allow for the well-known physiological phenomena of functional kidney ageing [14-15]. A marked variation may be observed in the metabolism and plasma levels of all classes of AAs, and may not be proportional to the degree of severity of CKD [16] compared to dialysis patients in whom significant amino acid losses may be elicited by dialytic procedures [17-19]. The difficulty of establishing alterations to AA kinetics should also be underlined, with regard not only to the discrepancies encountered in establishing the actual normal values of AAs in healthy subjects over the age of 65-70 years, but also in ascertaining the level of variations to AA plasma profile in age-matched CKD patient populations. Additional factors may complicate studies in this field, including the well-known differences in eating habits (meat-eaters, vegans, fisheaters and vegetarians) [20] and cultural differences between populations worldwide [21], in addition to a lack of consistency in the use of laboratory methods used to determine plasma levels of free amino acids [23], including pre-analysis storage procedures. Further to the differences detected in AA levels in arterial and peripheral venous blood, the analytical methods used are highly sensitive to storage times and temperature, particularly as blood sample are extremely susceptible to a wide variation in AA levels if taken whilst the patient is fasting or shortly after meals [24]. AA kinetics are subjected to irregular deviations caused by a gradual loss of glomerular-tubular function resulting in reduced power of the anabolic cellular pathway. Hypercatabolism and anabolic resistance in CKD are highly compromised in the elderly, particularly at a mitochondrial level, mainly muscle cells, due to increased insulin resistance, metabolic acidosis and to the role played by the products of glycosylation [25-26]. It is an acknowledged fact that to overcome this barrier and adequately maintain muscle mass, protein intake of at least 1.0$1.2 \mathrm{~g} / \mathrm{kg} /$ day [27] is required, although in the context of CKD, protein intake is strictly limited, based on the CKD stage of the patient, to a range of 0.8 to $0.3 \mathrm{~g} / \mathrm{Kg} / \mathrm{day}$, with the intent of preserving Residual Kidney Function (RKF) [5, 28]. Moreover, a high percentage of elderly uremic patients suffer from anorexia and display initial or advanced signs of Protein Energy Wasting (PEW), even in industrialised nations, due to the difficulty of maintaining an adequate calorie intake at levels as low as $30 \mathrm{KCal} / \mathrm{kg} / \mathrm{day}$ [29-31]. A 
limited intake of high-quality proteins and acceleration of the protein-amino acid catabolism with subsequent reduction of protein synthesis produced through the action of anorexigenic hormones and activation of pro-inflammatory cytokines, inevitably impinge on the amino acid metabolism, with AAs being used increasingly as a source of energy, particularly in states of CKD-associated malnutrition, [31] at the expense of a progressive decrease in body fat, and particularly, muscle mass. To slow down the progressive worsening of $\mathrm{CKD}$, protein intake should therefore be drastically reduced to $0.6 \mathrm{~g} / \mathrm{kg} /$ day (Low Protein Diet, LPD) or 0.3-0.4 g/kg/day (Very Low Protein Diet, VLDP), although essential AA supplementation is mandatory [32-33]. Plasma amino acid alterations may relate to individual AAs or groups of the same, although data obtained from comparison of healthy subjects over the age of 65 with subjects affected by stage $3 \mathrm{~b}-$ $4 \mathrm{CKD}$ are currently lacking. Garibotto et al. reported how the branched-chain AA metabolism, in particular leucin and valine, is compromised by an excessive catabolism at muscular level, with plasma and tissue levels of arginine, tyrosine, tryptophan, cysteine and other EAAs also affected [23,34]; however, these observations do not relate to the more representative, and prevalently affected, age group of the over-65s. Numerous studies have detected altered plasma levels of a series of AAs including valine and phenylalanine; unfortunately, also in this case, the populations studied did not relate to patients over the age of 65 . Moreover, the patients studied were prevalently diabetic and/or affected by other conditions and severe comorbidities. The rare reports relating to normal ranges for plasma AAs comprise a study published by Tan et Al [35], who analysed populations featuring different eating habits but with a mean age of 38.7 years. Plasma ranges relating to arterial and venous AA levels in CKD patients are provided in a paper by Aquilani et Al. [36]; the Author compared arterial and venous blood parameters from 11 patients over the age of 65 years affected by cardiorenal syndrome having an eGFR $<60 \mathrm{~mL} / \mathrm{min} . / 1.73 \mathrm{~m} 2$ versus those detected in the arterial blood of 8 healthy subjects; in this study, levels of all AAs were found to be lower in CKD patients compared to healthy subjects, although the detrimental effect of heart failure should be taken into account. An additional aspect of notable importance in patients with CKD is represented by the progressive onset of severe dysbiotic alterations affecting the microbiota and intestinal absorption, targeting particularly the tight-junctions of the intestinal wall [37-39]. On the one hand, a reduced protein intake results in a decrease in production of highly toxic uremic molecules such as PBUTs ( $p$-cresyl-sulfate, p-cresylglucuronide, indoxyl-sulfate, indole-3-acetic acid), whilst on the other, PBUTs are more readily absorbed due to the lack of containment by the intestinal barrier $[40,41]$; moreover, inflammation and toxicity associated with uraemia alter the intestinal microbial balance, thus enhancing formation of PBUTs through the transformation of aromatic AAs such as tyrosine and phenylalanine and degradation of tryptophan $[42,43]$. Since the ranges of plasma amino acids remain to be fully clarified in both in healthy elderly subjects and CKD patients at stages 3b-4 over the ages of 65-70 years, we set up an observational study to compare, although in a limited number of cases, the differences between healthy subjects and CKD patients, and to assess potential changes to the amino acid profile and blood chemistry and nutritional parameters in the groups studied. We simultaneously investigated the impact of CKD on intestinal inflammation based on the assay of faecal calprotectin such as on intestinal absorption based on the assay of zonulin which had not previously been studied and used as valid indicators in the course of moderate-advanced stages of CKD, as had conversely been the case for other chronic conditions that result in metabolic "inflammaging" [44-45]. Increased zonulin levels were correlated with an alteration of the tight-junction of the intestinal barrier, thus facilitating transfer of microbial antigens and a subsequent increase in release of lipopolysaccharides (LPS). Furthermore, zonulin levels correlated with cellular resistance to the action of insulin [4647]. LPS, particularly those deriving from Gram-negative bacteria mobilised in blood circulation, induce an inflammatory response elicited by the release of pro-inflammatory cytokines produced as a result of lympho-monocyte activation. Conversely, calprotectin 
is a protein expressed by neutrophils, the faecal quantity of which acts as a sensitive indicator of gastrointestinal inflammation [48-51]. Levels of these faecal markers illustrate the state of well-being of regulatory intestinal functions, proving to be valid tools not only in the follow-up assessment of chronic pathological conditions such as CKD, but also in stimulating the efficacy of therapies aimed at restoring the microbiota and absorptive function of the intestinal wall. The aims of this observational study of the protein and amino acid metabolism focus on a comparison between healthy volunteers and conservatively managed patients with stage $3 b-4$ CKD over the age of 65-70 years. We are confident that this study may indeed further encourage research in the specific field and an exchange of views between the authors of similar studies, somewhat lacking in literature, with a view to defining the kinetics, fate and variation of plasma amino acid levels, whilst not overlooking the important alterations of intestinal function in the course of CKD.

\section{Materials and Methods}

Eleven healthy volunteers aged 65 years and over (age $72.2 \pm 3.7-7$ males and 4 females) were compared with a group of twelve age-matched patients (age $74.6 \pm 4.2-7$ males and 5 females) affected by chronic kidney disease who had been pre-selected on the basis of eGFR values ranging between 29 and $44 \mathrm{~mL} / \mathrm{min} . / 1.73 \mathrm{~m} 2$ (CKD stages 3b-4). CKD patients were subjected to careful monitoring of prescriptions relating to conservativenutritional management of the disease both at the start of the outpatient study (T0) and at 12-month follow-up (T12), a period of time deemed sufficient to enable achievement of metabolic stability following adherence to a new dietary regimen and a new lifestyle. Patients were excluded from the study based on absence throughout the specific period of a metabolic steady state defined as: presence of acute or chronic inflammatory diseases, type I or II diabetes, malignant tumours, autoimmune diseases, treatment with steroids and/or immunosuppressant drugs, chronic pulmonary disease, malnutrition, cardiomyopathy with heart failure, liver diseases. Moreover, CKD patients with an eGFR > 44 and $<15 \mathrm{~mL} / \mathrm{min} . / 1.73 \mathrm{~m} 2$ and healthy volunteers with an eGFR $<80 \mathrm{~mL} / \mathrm{min} . / 1.73 \mathrm{~m} 2$ were excluded from the study. Between T0 and T12, patients recruited to the study were not provided with any form of nutritional/amino acid supplementation. From the start of the study, a dietary programme based on protein intake of $0.6 \pm 0.1 \mathrm{~g} / \mathrm{kg} /$ day, calorie intake of $>30 \mathrm{Kcal} / \mathrm{kg} /$ day and phosphate intake of $<1,000 \mathrm{mg} /$ day was prescribed. Protein intake was made up of approximately 50\% animal proteins; to boost compliance with the diet prescribed a full range of highly palatable protein-free food products were used. Healthy volunteers were asked to stick to their standard diet following initial assessment by an expert renal nutritionist. The following parameters were taken into account when assessing the two populations: bioelectrical impedance analysis performed by the same operator using the same instrument (Renal EFG50 KHz; EFG Diagnostic Ltd, Belfast, Northern Ireland), Body Mass Index, blood count, iron pool, electrolyte panel, 24-hour proteinuria, Urea Nitrogen Appearance to measure protein intake [52,53], PTHi, CReactive Protein (CRP), plasma protein profile, immunoglobulins, $\mathrm{pH}$ and plasma bicarbonataemia. Following the pre-selection assessment of eGFR, a stricter estimation of RKF was carried out based not only on creatinine clearance [54,55॰, but also on calculation of GFR obtained from $24 \mathrm{~h}$ urine collection and estimation of residual creatinine clearance $(\mathrm{KrCr})$ and urea (KRUREA) using the formula (KRCr +KRUREA)/2 (defined Measured Glomerular Filtration rate - MGFR) [56-57]. A comparison was also conducted between healthy volunteers and CKD patients at MGFR to assess values obtained for the equations of the Prediction Modification of Diet in Renal Disease Study Group (MDRD) and the Chronic Kidney Disease Epidemiology Collaboration (CKD-EPI) [58๑. Both eGFR and MGFR were normalised to the body surface area of each patient and healthy volunteers. Samples were obtained in the morning on an empty stomach 12 hours after the last meal. The amino acid panel was deemed as comprising 20 amino acids (EAAs, NEAAs, BCAAs). 
Faecal zonulin was determined using an ELISA kit (Zonulin Stool - ELISA, DRG Instruments Gmbh, Germany): normal faecal values in healthy volunteers were $<60 \mathrm{\eta g} / \mathrm{ml}$. Calprotectin was determined by means of immunoenzymatic assay and measured using a Chorus TRIO instrument (DIESSE Diagnostica Senese S.p.A, Italy): normal values of faecal Calprotectin were $<50 \mathrm{mg} / \mathrm{g}$ faeces.

This study was based on an observational design and each patient signed an informed consent form agreeing to use and processing of his or her personal data. The study was approved by the Ethics Committee of the local Health Authorities.

\subsection{Method of Detemination of Amino Acids}

To ensure the highest degree of reliability of results, accurate methods were applied in the sampling and collection of plasma from arterial blood for use in AA concentration assays: before and after the dialysis session॰17-19]. $10 \mathrm{~mL}$ of whole blood were collected in 2 heparinized test tubes and stored at room temperature (to avoid issues of thermal hydrolysis). Plasma was separated within 2 hours of collection by centrifuging at 3000 rpm for 10 minutes. The plasma thus obtained was frozen in $2 \mathrm{~mL}$ cryogenic test tubes at a temperature of $220 \mathrm{C}$. The plasma collected was then mixed to obtain a homogenous solution, and 4-mL samples were obtained and stored in a freezer in two 2-mL test tubes. Within 2 days of collection, samples were transferred on dry ice to the laboratory for final storage. The analytical method required "pre-column" derivation of free amino acids by ortho-phthalaldehyde and 9-fluorenyl-methyl-chloroformate for the recognition of primary and secondary amino acids, respectively. Derivates were separated by means of reverse-phase liquid chroma- tography and revealed using a fluorometer X-LC (model 3020FP). Analysis was carried out on a $1 \mathrm{~mL}$ sample of a standard mixture or serum. Sample testing was invariably preceded by analysis of a standard mixture to verify system efficiency. Graduated concentrations (from 29 to $233 \mathrm{mM} / \mathrm{mL}$ ) of the standard mixture were used to establish the calibration curve for subsequent use in quantitative analysis. To increase reliability of the results, each sample was analysed in triplicate and each amino acid was quantified based on the mean obtained from three determinations. The results were obtained by injecting $1 \mathrm{~mL}$ of derived mixture and simultaneously measuring absorbance at $338 \mathrm{~nm}$ and $262 \mathrm{~nm}$. Samples were tested using an amino acid analyser HPLC X-LC-Jasco linked to an HP ProDesk elaborator. AA concentrations were expressed in both $\mathrm{ml} / \mathrm{L}$ and $\mathrm{mg} / \mathrm{dl}$ and compared with standard values in our laboratory. Twenty AAs were determined including Total AAs (TAAs), Essential AAs (EAAs) including Branched-Chain AAs (BCAAs) and Non-Essential AAs (NEAAs).

\subsection{Statistical Analysis}

The Shapiro-Wilk test supported by visual inspection was used to assess the normality of distribution of continuous variables. Several variables violated the normality assumption, but violations were not marked. Accordingly, the central tendency and dispersion of continuous variables were reported as mean \pm SD and hypothesis testing was based on non-parametric statistics, checked using also parametric tests. Descriptive statistics for categorical variables were reported as $\mathrm{N}$ (percent frequency). Between-group comparisons (CKD patients at T0 vs healthy subjects and CKD patients at T12 vs healthy subjects) were carried out by Mann-Whitney U-test (checked using two-sample t-test) and by the Chi-square test for continuous and categorical variables, respectively. The association between couples of variables was assessed by correlation analysis, computing both Spearman and Pearson correlation coefficient r. A p-value $<0.05$ was considered statistically significant. All analyses were carried out using the SAS/STAT statistical package, release 9.4 (SAS Institute Inc., Cary, NC, U.S.A.).

\section{Results}


Four patients affected by stage $3 b-4$ CKD dropped out of the study: one due to a deterioration of MGFR to stage 5 CKD (MGFR < $15 \mathrm{~mL} / \mathrm{min} . / 1,73 \mathrm{~m} 2$ ), two following a refusal during the first month of the study to adhere to the new dietary regimen and one due to onset of an intercurrent subacute/acute lung infection. Statistical comparisons were therefore carried out on the eleven healthy volunteers and the remaining eight patients affected by stage 3b-4 CKD, aged 73.5 ○6.8 (4 females \& 4 males). Two of the healthy control subjects and 5 CKD patients were taking antilipemic agents (statins). Calcaemia and phosphoremia levels were well controlled; CKD-elicited derangement of mineral balance linked to the calcium-phosphorus equilibrium was unmasked by a progressive secondary hyperparathyroidism manifested as a result of renal enzyme activity in transforming vitamin D (25-OH-D3) into its active metabolites (1,25-OH-D3). Pathological levels of CRP (normal ranges $0.8-1.0 \mathrm{mg} / \mathrm{L}$ ) were evident at 12 months (T12), although compared to $\mathrm{T} 0$, the difference did not reach statistical significance (Tab.1).

Table 1. Biochemical, PTHi and inflammatory plasmatic assessment.

\begin{tabular}{cccc}
\hline & $\begin{array}{c}\text { Healthy Subjects } \\
\mathbf{( N = 1 1 )}\end{array}$ & $\begin{array}{c}\text { CKD patients at } \\
\text { T0 } \mathbf{( N = 8 )}\end{array}$ & $\begin{array}{c}\text { CKD } \\
\text { patients at T12 } \\
\mathbf{( N = 8 )}\end{array}$ \\
\hline Total Cholesterol, mg/dL & $222.27 \pm 23.09$ & $197.25 \pm 39.57$ & $193.13 \pm 34.69^{+}$ \\
HDL Cholesterol, mg/dL & $64.18 \pm 18.87$ & $70.13 \pm 22.99$ & $77.86 \pm 32.19$ \\
LDL Cholesterol, mg/dL & $137.09 \pm 22.52$ & $110.63 \pm 22.20^{+}$ & $102.50 \pm 20.79 \ddagger$ \\
Triglycerides, mg/dL & $98.91 \pm 69.06$ & $75.63 \pm 35.48$ & $75.50 \pm 19.57$ \\
Glycemia, mg/dL & $94.36 \pm 8.03$ & $94.50 \pm 10.41$ & $94.50 \pm 11.21$ \\
AST, U.I. & $20.55 \pm 3.39$ & $20.38 \pm 6.72$ & $18.63 \pm 2.97$ \\
ALT, U.I. & $16.64 \pm 2.58$ & $17.38 \pm 6.67$ & $13.50 \pm 4.66$ \\
$\gamma$ GT, U.I. & $20.64 \pm 8.18$ & $31.63 \pm 35.70$ & $27.50 \pm 29.27$ \\
Creatine phosphokinase, U.I. & $100.27 \pm 59.73$ & $141.38 \pm 94.21$ & $130.63 \pm 122.35$ \\
Sodium, mmol/L & $141.03 \pm 2.12$ & $141.91 \pm 1.78$ & $141.53 \pm 1.16$ \\
Potassium, mmoL/L & $4.31 \pm 0.41$ & $4.38 \pm 0.42$ & $4.35 \pm 0.41$ \\
Calcemia, mg/dL & $9.73 \pm 0.55$ & $9.19 \pm 0.48$ & $9.35 \pm 0.68$ \\
Phosphate, mg/dL & $3.57 \pm 0.58$ & $3.41 \pm 0.33$ & $3.70 \pm 0.58$ \\
Ionized Calcium, mmol/L & $5.06 \pm 0.38$ & $4.94 \pm 0.27$ & $4.84 \pm 0.18$ \\
Uric Acid, mg/dL & $4.24 \pm 0.49$ & $6.01 \pm 3.01$ & $5.16 \pm 1.12^{\dagger}$ \\
C Reactive Protein, mg/L & $1.45 \pm 1.85$ & $1.76 \pm 1.26$ & $3.04 \pm 5.42$ \\
PTHi, pm/mL & $64.35 \pm 22.40$ & $202.31 \pm 98.70 \S$ & $171.35 \pm 163.58 \ddagger$ \\
\hline
\end{tabular}

Table 2 highlights the onset of CKD-elicited anaemia featuring reduced iron levels and concomitant impoverishment of iron reserves. Nutritional deficit was emphasized by a downward, although not statistically significant, trend in total plasma proteins and a progressive decrease of C3. Inflammaging present in the CKD stages studied was indirectly confirmed by the $\lambda$ component of serum proteins, despite the absence of serious acute, subacute or chronic inflammatory conditions throughout the 12-month follow-up period.

Table 2. Plasmatic Hematological and Immunological parameters. ${ }^{\dagger}: \mathrm{p}<0.05$ for the comparison with Healthy subjects at T0; $\ddagger$ : $<<0.01$ for the comparison with Healthy subjects at T0;§: $p<0.001$ for the comparison with Healthy subjects at T0;T0: study start; T12: 12 months after study start

\begin{tabular}{ccc}
$\begin{array}{c}\text { Healthy Subjects } \\
(\mathbf{N}=\mathbf{1 1})\end{array}$ & $\begin{array}{c}\text { CKD patients at T0 } \\
(\mathbf{N}=\mathbf{8})\end{array}$ & $\begin{array}{c}\text { CKD patients at T12 } \\
(\mathbf{N}=\mathbf{8})\end{array}$ \\
\hline $14.16 \pm 1.20$ & $11.91 \pm 1.01 \S$ & $11.85 \pm 1.12 \S$
\end{tabular}

$\begin{array}{llll}\mathrm{Hb}, \mathrm{g} / \mathrm{L} & 14.16 \pm 1.20 & 11.91 \pm 1.01 \S & 11.85 \pm 1.12 \S\end{array}$




$\begin{array}{cccc}\mathrm{RBC}, \mathrm{mm}{ }^{3} & 5.39 \pm 6.95 & 4.23 \pm 2.84 \S & 4.25 \pm 3.22 \S \\ \text { Iron levels, } \mu \mathrm{g} / \mathrm{dL} & 106.09 \pm 26.69 & 104.63 \pm 46.03 & 72.38 \pm 32.76^{\ddagger} \\ \text { transferrin, mg/dL } & 268.95 \pm 54.98 & 252.75 \pm 50.09 & 244.75 \pm 36.17 \\ \text { ferritin, } \mu \mathrm{g} / \mathrm{L} & 175.60 \pm 93.28 & 80.06 \pm 63.91^{+} & 78.97 \pm 60.65^{+} \\ \text {WBC, mm } & 6270.9 \pm 2055.4 & 6568.8 \pm 1509.7 & 7258.8 \pm 1413.2 \\ \text { Lymphocytes, mm }{ }^{3} & 2123.6 \pm 745.1 & 1543.9 \pm 843.5 & 1875.0 \pm 656.3 \\ \text { IgG, mg/dL } & 1080.5 \pm 263.7 & 1134.6 \pm 219.1 & 1146.0 \pm 259.6 \\ \text { IgA, mg/dL } & 202.48 \pm 79.95 & 194.91 \pm 115.62 & 250.14 \pm 138.91 \\ \text { IgM, mg/dL } & 120.61 \pm 72.28 & 79.94 \pm 65.23 & 85.51 \pm 88.43 \\ \text { C3, mg/dL } & 120.13 \pm 28.05 & 108.74 \pm 37.62 & 95.89 \pm 21.93 \\ \text { C4, mg/dL } & 26.61 \pm 6.94 & 27.09 \pm 10.90 & 25.76 \pm 8.58 \\ \text { Total Protein, g/dL } & 7.25 \pm 0.39 & 6.73 \pm 0.48^{+} & 7.07 \pm 0.57 \\ \text { Albumin, g/dL } & 4.21 \pm 0.23 & 3.99 \pm 0.22 & 4.13 \pm 0.18 \\ \text { Protein } \lambda \text {-zone, \% } & 11.87 \pm 1.46 & 15.39 \pm 1.00 \S & 15.02 \pm 2.74^{+}\end{array}$

Bioelectrical impedance analysis continues to represent a valid assessment tool for nutritional status for use in routine monitoring: the results yielded confirm whether uraemia has affected the nutritional-calorie status, demonstrated by a significant decrease of the phase angle due prevalently to increased extracellular body water and a nonsignificant tendency towards reduction of muscle mass (Tab.3).

Table 3. Anthropometric and Bioimpedance measures.

\begin{tabular}{cccc}
\hline & \multicolumn{3}{c}{ Healthy Subjects CKD patients at CKD patients at } \\
& $\mathbf{( N = 1 1 )}$ & T0 $(\mathbf{N}=8)$ & T12 $(\mathbf{N}=\mathbf{8})$ \\
\hline Age, years & $72.27 \pm 3.74$ & $73.56 \pm 6.90$ & $74.56 \pm 6.90$ \\
Weight, Kgs & $64.50 \pm 12.80$ & $62.44 \pm 9.43$ & $62.76 \pm 9.05$ \\
Height, cm & $164.55 \pm 7.62$ & $156.00 \pm 13.26$ & $156.00 \pm 13.26$ \\
Rz, Ohm & $536.27 \pm 39.97$ & $497.00 \pm 72.28$ & $515.50 \pm 113.19$ \\
Xc, Ohm & $52.15 \pm 12.42$ & $42.25 \pm 10.82$ & $42.25 \pm 17.38$ \\
Phase Angle, grades & $5.16 \pm 0.60$ & $4.50 \pm 0.73$ & $4.22 \pm 0.67 \ddagger$ \\
Total Body Water, \% & $35.65 \pm 16.60$ & $53.55 \pm 8.74^{+}$ & $55.93 \pm 9.20^{+}$ \\
Extracellular Body Water, \% & $19.25 \pm 8.48$ & $44.36 \pm 14.88 \S$ & $55.75 \pm 4.39 \S$ \\
Intracellulare Body Water, \% & $44.65 \pm 4.10$ & $41.09 \pm 14.62$ & $40.69 \pm 10.06$ \\
Body Fat Mass, Kgs & $21.91 \pm 2.40$ & $16.44 \pm 3.84 \S$ & $19.97 \pm 9.96$ \\
Fat Free Mass, Kgs & $27.55 \pm 2.85$ & $44.30 \pm 8.42 \S$ & $44.00 \pm 10.03 \S$ \\
Body Cellular Mass, Kgs & $24.86 \pm 2.79$ & $20.78 \pm 4.20^{+}$ & $19.84 \pm 6.52$ \\
Body Muscle Mass,kgr & $27.55 \pm 2.85$ & $26.35 \pm 5.14$ & $24.21 \pm 6.07$ \\
Body Mass Index & $24.86 \pm 2.79$ & $24.84 \pm 1.98$ & $25.31 \pm 2.31$ \\
Resting Metabolic Rate, Kcal & $1385.1 \pm 68.0$ & $1355.0 \pm 121.5$ & $1298.8 \pm 144.8$ \\
\hline
\end{tabular}

It should also be taken into account that, despite prescription of a low-protein diet of $0.6 \pm 0.1 \mathrm{~g} / \mathrm{kg} /$ day, patients did not comply fully with the diet prescribed, as attested to by Urea Nitrogen Appearance. Indeed, at T12, although only 3/8 (37.5\%) patients had adhered rigorously to the prescribed diet, a substantial tendency to adapt to the desired protein intake was observed. The manifest decrease in RKF was confirmed by MGFR, based on both eGFR derived from calculation of MDRD and CKD-EPI. The parameters used to calculate eGFR (MDRD, CKD-EPI) based on creatine alone, displayed a predictable overestimation versus MGFR in CKD patients. However, the correlations between MGFR and eGFR in healthy subjects at T0 and T12 were aligned (R Spearman > $0.8 ; \mathrm{p}<0.0001)$. Plasma $\mathrm{pH}$ was maintained unchanged by metabolic/respiratory 
compensatory phenomena, although the decrease in plasma bicarbonates revealed onset of relatively well compensated metabolic acidosis (Tab.4).

Table 4. Evaluation parameters of Renal Function. ${ }^{\dagger}: \mathrm{p}<0.05$ for the comparison with Healthy subjects at T0; $:$ p $<0.01$ for the comparison with Healthy subjects at T0; $\S_{\bullet}$ p $<0.001$ for the comparison with Healthy subjects at T0; T0: study start; T12:12 months after study start. .N.A. Urea Nitrogen Appearance, g/kg/day;.

\begin{tabular}{|c|c|c|c|}
\hline & $\begin{array}{c}\text { Healthy } \\
\text { Subjects } \\
(\mathrm{N}=11)\end{array}$ & $\begin{array}{c}\text { CKD patients at } \\
\text { T0 }(\mathrm{N}=8)\end{array}$ & $\begin{array}{c}\text { CKD patients at T12 } \\
(\mathrm{N}=8)\end{array}$ \\
\hline Blood Urea Nitrogen, mg/dL & $11.47 \pm 3.52$ & $42.44 \pm 15.07 \S$ & $43.86 \pm 16.09 \S$ \\
\hline Creatinine, $\mathrm{mg} / \mathrm{dL}$ & $0.81 \pm 0.16$ & $1.99 \pm 0.53 \S$ & $2.12 \pm 0.51 \S$ \\
\hline diuresis $24 \mathrm{~h}, \mathrm{~mL}$ & $1640.9 \pm 417.0$ & $2131.3 \pm 633.5$ & $1993.8 \pm 526.1$ \\
\hline U.N.A., g/Kg/day & $1.17 \pm 0.13$ & $1.05 \pm 0.27$ & $0.89 \pm 0.21^{\dagger}$ \\
\hline MGFR, $\mathrm{mL} / \mathrm{min} . / 1.73 \mathrm{~m}^{2}$ & $87.70 \pm 7.45$ & $26.99 \pm 2.80 \S$ & $22.93 \pm 3.25 \S$ \\
\hline MDRD, mL/min/1,73 m² & $85.97 \pm 17.40$ & $31.85 \pm 9.40 \S$ & $30.83 \pm 7.88 \S$ \\
\hline CKD-EPI, mL/min./1.73 m² & $85.91 \pm 16.64$ & $30.41 \pm 10.05^{\S}$ & $30.06 \pm 8.17 \S$ \\
\hline proteinuria $24 \mathrm{~h}, \mathrm{mg} / 24 \mathrm{~h}$ & $94.73 \pm 76.39$ & $533.63 \pm 469.93 \ddagger$ & $324.04 \pm 316.12$ \\
\hline $\mathrm{pH}$ & $7.36 \pm 0.02$ & $7.34 \pm 0.03$ & $7.35 \pm 0.04$ \\
\hline $\begin{array}{l}\text { plasmatic bicarbonates, } \\
\text { mmol/L }\end{array}$ & $26.69 \pm 2.18$ & $23.76 \pm 0.89 \ddagger$ & $23.03 \pm 1.42 \ddagger$ \\
\hline
\end{tabular}

Table 5. illustrates and confirms how in the moderate-advanced stages of CKD intestinal function undergoes a series of alterations linked to the uremic setting. Faecal zonulin and calprotectin act as ideal markers for intestinal dysbiosis produced by an altered intestinal absorption and inflammation that follows a significant upward trend in line with progression of CKD.

Table 5. Fecal intestinal markers.

\begin{tabular}{cccc}
\hline & Healthy & CKD patients at T0 CKD patients at T12 \\
& Subjects $(\mathbf{N = 1 1 )}$ & $\mathbf{( N = 8 )}$ & $(\mathbf{N = 8 )}$ \\
\hline Fecal Calprotectin, $\mathrm{ng} / \mathrm{mL}$ & $30.25 \pm 27.62$ & $78.37 \pm 87.42$ & $95.60 \pm 53.26^{\ddagger}$ \\
Fecal Zonulin, $\mathrm{mg} / \mathrm{g}$ & $54.96 \pm 32.73$ & $142.67 \pm 114.42$ & $231.43 \pm 181.54 \ddagger$ \\
\hline
\end{tabular}

The panel of 20 AAs examined displayed several variations: a significant increase in 4/20 NEAAs (20\%) including asparagine, aspartic acid and serine, which maintained high plasma levels as CKD progressed; glycine showed a continued tendency towards a delayed, although significant, at T12. Four out of twenty AAEs (20\%) displayed a significant, stable increase of histidine in line with the evolution of RKF, whilst deterioration of MGFR levels of threonine, arginine and tryptophan were characterised by a delayed onset. All other AAs, in particular BCAAs, remained unaffected by uremic status compared to healthy subjects. Generally speaking, however, TAAs displayed a modest, although significant, rise (approx. 17\%) as uremic status worsened (Tab.6).

Table 6. Plasma amino Acid Levels, $\mu \mathrm{mol} / \mathrm{mL} .+\mathrm{p}<0.05$ for the comparison with Healthy subjects at T0; $¥: p<0.01$ for the comparison with Healthy subjects at T0; $\S: p<0.001$ for the comparison with Healthy subjects at T0; T0: study start; T12:12 months after study start;

\begin{tabular}{cccc}
\hline & $\begin{array}{c}\text { Healthy Subjects } \\
(\mathbf{N = 1 1 )}\end{array}$ & $\begin{array}{c}\text { CKD patients at } \\
\text { T0 }(\mathbf{N}=\mathbf{8})\end{array}$ & $\begin{array}{c}\text { CKD patients at T12 } \\
(\mathbf{N}=\mathbf{8})\end{array}$ \\
\hline Asparagine & $4.84 \pm 1.78$ & $17.08 \pm 4.32 \S$ & $14.39 \pm 5.50 \S$ \\
Glutamic Acid & $159.49 \pm 21.75$ & $180.29 \pm 23.74$ & $179.92 \pm 46.72$ \\
Aspartic Acid & $10.51 \pm 2.12$ & $18.28 \pm 6.3 \ddagger$ & $19.57 \pm 15.65^{\dagger}$
\end{tabular}




\begin{tabular}{cccc} 
Serine & $31.60 \pm 6.77$ & $49.51 \pm 11.34 \ddagger$ & $40.41 \pm 7.35^{\dagger}$ \\
Glutamine & $147.22 \pm 27.46$ & $156.69 \pm 95.37$ & $229.41 \pm 131.79$ \\
Hystidine & $22.24 \pm 3.72$ & $33.49 \pm 18.47 \ddagger$ & $63.13 \pm 31.61^{\ddagger}$ \\
Glycine & $123.63 \pm 34.81$ & $157.44 \pm 49.75$ & $176.66 \pm 66.84^{\dagger}$ \\
Threonine & $65.18 \pm 14.40$ & $76.26 \pm 14.96$ & $89.34 \pm 29.27^{\dagger}$ \\
Alanine & $348.94 \pm 84.88$ & $340.82 \pm 58.70$ & $316.25 \pm 39.76$ \\
Arginine & $95.73 \pm 15.79$ & $112.37 \pm 34.34$ & $158.22 \pm 61.73^{\ddagger}$ \\
Tyrosine & $54.69 \pm 12.41$ & $48.75 \pm 10.93$ & $47.66 \pm 7.48$ \\
Cysteine & $207.54 \pm 56.71$ & $217.92 \pm 36.15$ & $208.18 \pm 54.18$ \\
Valine & $172.90 \pm 19.25$ & $183.10 \pm 46.29$ & $168.03 \pm 35.51$ \\
Methionine & $19.12 \pm 3.48$ & $20.39 \pm 5.89$ & $21.40 \pm 5.23$ \\
Tryptophane & $34.53 \pm 4.95$ & $36.15 \pm 8.05$ & $48.61 \pm 21.17^{\dagger}$ \\
Phenylalanine & $45.11 \pm 4.76$ & $51.33 \pm 8.20^{+}$ & $48.63 \pm 6.45$ \\
Isoleucine & $47.62 \pm 8.39$ & $51.11 \pm 18.97$ & $50.46 \pm 11.84$ \\
Leucine & $90.32 \pm 15.38$ & $91.20 \pm 29.24$ & $88.59 \pm 20.23$ \\
Lysine & $125.23 \pm 15.70$ & $139.14 \pm 22.40$ & $134.89 \pm 17.86$ \\
Proline & $196.71 \pm 63.87$ & $208.06 \pm 55.76$ & $233.29 \pm 125.77$ \\
Total Amino Acids & $2003.2 \pm 239.9$ & $2189.4 \pm 300.1$ & $2337.1 \pm 419.6^{\dagger}$ \\
Branched Amino Acids & $310.85 \pm 40.79$ & $325.41 \pm 91.84$ & $307.08 \pm 66.30$ \\
Esential Amino Acids & $622.25 \pm 66.72$ & $682.17 \pm 121.71$ & $713.08 \pm 140.98$ \\
Non Essential Amino Acids & $1380.9 \pm 218.8$ & $1507.2 \pm 222.7$ & $1624.0 \pm 317.3$ \\
\hline
\end{tabular}

The ratio between AAEs (including BCAAs)/NEAAS remained unchanged in healthy subjects (ratio: 0.67), CKD patients at T0 (ratio: 0.66) and CKD patients at T12 (ratio: 0.62). Lastly, Table 7 provides a summary of the correlations detected between AAs and MGFR. Only three AAs displayed a significant correlation with RKF.

Table 7. Correlation coefficients between selected amino acids and MGFR.

\begin{tabular}{ccc}
\hline & Spearman's r & Pearson's r \\
\hline Cystine & $0.88(\mathrm{p}=0.007)$ & $0.85(\mathrm{p}<0.007)$ \\
Histidine & $0.55(\mathrm{p}=0.17)$ & $0.67(\mathrm{p}=0.007)$ \\
Glicine & $0.64(\mathrm{p}=0.10)$ & $0.71(\mathrm{p}=0.047)$ \\
\hline
\end{tabular}

\section{Discussion}

It is widely acknowledged that particularly in elderly patients, CKD produces: a tendency towards hyperuricemia, secondary hyperparathyroidism, anaemia caused by a deficit in renal activation of endogenous erythropoietin and progressive iron deficiency, decrease in total plasma proteins and reduction of the phase angle due to an increase of extracellular water and decrease of body fat and muscle mass [59-61]. The prescription of a low-protein diet produces a significant impact on the intake and kinetics of AAs. Generally, protein intake in uremic stages 3-5 CKD patients is reduced and a very low protein diet (VLPD) or low protein diet (LPD) is prescribed. Regrettably, methods employed to monitor dietary compliance are frequently based on the use of nutritional interviews or questionnaires, with the absence of expert renal nutritionists in hospital wards worldwide playing a key contributory role. Very few authors take into account the well-validated calculation of Urea Nitrogen Appearance, which should indeed always support estimation and follow-up in CKD [52,53]. Accordingly, the prescription of a VLPD is associated with the administration of large amounts of tablets or sachets as an AA supplement, with these compound containing calcium salts and a mix of amino acids and their keto-analogues containing both EAAs and BCAAs but not NEAAs. Compliance with the prescribed diet may be negatively affected by this large number of tablets or sachets to be taken daily, mainly at low-protein meal times (a 65kg patient will take 10-12 tablets/day/365 days/year), which may elicit gastrointestinal side effects and alterations to 
the calcium metabolism. Our group routinely prescribes a LPD of $0.6-0.7 \mathrm{~g} / \mathrm{kg} / \mathrm{day}$. The nutritional prescription of LPD, although failing to yield optimum results in our study, was supplemented by the use of highly palatable protein-free foods and products. It should therefore be borne in mind that protein intake will need to be monitored and assessed during nutritional follow-up. Indeed, studies focussing on the protein and amino-acid metabolisms frequently report high numbers of dietary non-compliance right from the start of treatment, with percentages exceeding 50\% in the case of VLPD using alpha-kappa keto-analogues [62-66]. Monitoring conducted by means of dietary interviews is frequently unreliable due to the negative motivation in patients in referring the precise outcome of dietary changes in the hope of avoiding dialysis or in the inaccurate interpretation of changes made to their diet, often caused by the lack of support and assistance from family members [67]. In this study, we associated dietary monitoring conducted by means of interview with the patient and caregivers of both healthy subjects and CKD patients, with an analytic process aimed at quantifying the output of urinary and non-urea nitrogen, thus yielding reliable findings with regard to protein intake. Likewise, correlations between protein intake and amino acids may be deceptive in accurately estimating RKF, therefore justifying why we chose to use MGFR based on the formula (KRCr + KRUREA)/2. This determination should be only be performed in patients in a metabolic steady state to avoid the negative interference of hypercatabolic states that may result in alterations to the generation and clearance of urea. Furthermore, KRUREA amortizes the overestimation of values obtained by means of $\mathrm{KRCr}$ as urinary creatinine, even in the more advanced stages of CKD, and continues to be raised due to the wellknown tubular secretion of creatine in the urine and concomitant decrease in plasma levels. It is moreover crucial to bear in mind that eGFR calculated on the basis of MDRD and CKD-EPI, calculation that can be achieved on numerous websites, is based solely on plasma creatinine, age, sex and ethnic origin, whilst failing to account for anthropometric parameters such as height, weight, BMI and body surface area. Recourse to a personalised rather than standardized form of precision medicine and nutrition should be advocated, bearing in mind that healthy subjects over the age of 65-70 years fail to conserve a mean renal function of $>100 \mathrm{~mL} / \mathrm{min}$. due to the acknowledged phenomena of renal senescence resulting in a GFR loss of at least $0.73 \mathrm{~mL} / \mathrm{min}$./year after the age of 30-40 years [69-71]. With regard to plasma AA levels, no literature reports to date have suggested normality ranges validated in patients over the age of 65-70 years, and even less so in stage 3b-4 CKD patients. Moreover, it should be highlighted how an additional inhibition of mitochondrial cellular activity in elderly patients due to a decreased sensitivity to insulin and, in CKD patients, to hypercatabolism and inflammation, hinders the adequate incorporation and use of AAs at a cellular level, particularly in myocytes, thus resulting in an increase in plasma levels of AAs accompanied by impoverishment of muscle mass [25] and increased release of AAs into the venous system, further impeding reliable estimation of the fate of AAs in the moderate/advanced stages $3 b-4$ of CKD. In the course of $\mathrm{CKD}$, this phenomenon is associated with a reduced residual renal clearance and tubular reabsorption of small molecules, including AAs, all of which amplified by a state of acidaemia/metabolic acidosis [72,73]. In the present study, metabolic/nutritional balance was reasonably maintained as shown by the ratio between AAEs/NEAAs which remained unchanged in healthy subjects and CKD patients at both T0 and T12. Other authors have reported a correlation between kidney function and increased cysteine levels, largely caused by mitochondrial dysregulation associated with uraemia, although these studies were performed in younger patients with non-advanced stages of CKD [74]; this phenomenon was not confirmed in our study. Mahbub et Al. [75] conducted a study on a vast population, subsequently highlighting the wide inconsistency and evident contrasts between AA plasma levels, with particular regard to BCAAs and phenylalanine, although also in this case the data obtained related to a young population affected by lesser degrees of kidney failure: indeed, in the worst percentile examined in this study, mean age corresponded to 59 years, with an eGFR of $70.9 \mathrm{~mL} / \mathrm{min} . / 1.73 \mathrm{~m} 2$, leading the 
authors to conclude that an increase in leucine and tryptophan correlated with a decline in GFR resulted in these three AAs being taken as indicators of CKD progression. These findings have not been confirmed by other authors [76-80] or by data obtained in our study. Further studies have reported increased levels of glycine, cystine and valine, although in the presence of different stages of CKD [81,82]. Plasma levels of BCAAs remain unchanged at the CKD stages we studied, likely due to the fact that our patients' kidneys still exerted an avid uptake of BCAAs and no significant influences were observed [83] as a result of a contained level of CKD "inflammaging" and, despite patients' advanced age, outpatient monitoring had been successful in preventing onset of an overt state of malnutrition/sarcopenia [48,79]. It is likely therefore that the correlations observed between AAs and RKF were not statistically relevant at these stages of CKD, although an association was detected between MGFR and glycine, histidine and cystine (Tab.7). Due to the presence of micro-inflammation, CKD has the potential to alter the mitochondrial-lysosomal function of cystine, although in our case studies, plasma levels of cystine, in line with previous findings, maintained similar levels compared to the group of healthy volunteers [84]. Glutamine is an amino acid of paramount importance in maintaining a normal anabolic-catabolic equilibrium in view of its crucial role in acid-base balance in the kidney as a self-defence mechanism against deamination and particularly in limiting the presence of ammonia in the brain [25]; even in CKD patients, glutamine reserves derive largely from protein degradation in muscle mass, thus representing a compensatory process against CKD [85]. Mair et $\mathrm{Al}$ [86] recently reported a finding of compromised tubular secretion of glutamine which increased progressively as CKD advanced towards more severe stages 4-5; in our study, we observed a 56\% increase in glutamine at T12 compared to healthy subjects, although statistical significance was not reached. An increase in histidine levels was detected in CKD patients versus healthy controls of $+184 \%$ and in glycine of $+43 \%$ after 12 months of conservative management; however, histidine levels have only rarely been reported during studies investigating CKD; a few specific studies do however mention high levels of histidine in the context of CKD $[82,87]$. Despite the beneficial role of arginine in protecting the endothelial system as a vasodilator through its action on nitric oxide and its singular insulin genetics, there is still ongoing debate as to the negative effects ascribed to methylation of arginine and consequent proteolysis resulting in a potential increase of toxic molecules such as asymmetric dimethylarginine (ADMA), symmetric dimethylarginine (SDMA) and Nmonomethyl-1-arginine (NMMA) [88]; moreover, no literature reports to date have described alterations to arginine plasma levels. To the best of our knowledge, no studies have addressed the issue of threonine levels, whilst tryptophan levels have been studied by Konje et Al. [89] in a group of patients affected by stages 3-5 CKD. This study found a positive correlation between tryptophan plasma levels and incidence of cardiovascular events, although the tryptophan plasma levels detected in patients with a mean age ranging from 54 to 57 years were far higher $(61.4-71.4 \mu \mathrm{mol} / \mathrm{mL})$ than those observed in our study (T0: $36.15 \pm 8.05, \mathrm{~T} 12: 48.61 \pm 21.17 \mu \mathrm{mol} / \mathrm{mL}$ ). The main limitation of our study is represented by the small number of patients studied, who demonstrated a modest, but statistically significant $17 \%$ increase in level of TAAs; however, it is clear that these values display a tendency towards increasing, and it may therefore follow that other AAs could behave in a similar manner as RKF falls below $15 \mathrm{~mL} / \mathrm{min}$. It would be of interest to study AA levels and intestinal absorption in stage 5 of CKD, although at this stage it may be more complicated to investigate AAs and dietary compliance due to the availability of a potentially brief follow-up period on the basis of increased mortality and high incidence of drop-out by patients progressing to dialysis treatment [90]. Furthermore, the effectiveness of VLPD compared to LPD on RKF progression is still debated [91]. With regard to the impact of CKD on intestinal function, to date, no studies have reported on the variations observed in intestinal permeability on the basis of levels of faecal zonulin in the course of CKD, with even the most recent publications referring solely to determination of plasma levels. Likewise, no studies have been published relating to the 
presence of intestinal inflammation with uremic dysbiosis, detected using a sensitive marker of inflammation such as faecal calprotectin, in the course of CKD.

\section{Conclusions}

Whilst parameters linked to the evolution of CKD are indisputable, a series of discrepancies are present in literature with regard to levels of single AAs or classes of AAs in CKD. These reports are significantly affected by: gender discrepancies, diverse methods used in analytical determination, differences between western and eastern eating habits, nutritional status and variations, pre-analytical and analytical procedures employed in determination of plasma AAs. In the present study, advanced age beyond 65-70 years in both healthy subjects and CKD patients likely represented the most significant factor when compared to the metabolism of younger patients and controls. It remains to be clarified which and to what extent AAs are implicated at an anabolic level in protein synthesis. The findings highlighted following use of intestinal faecal markers demonstrating a negative impact of uraemia on intestinal permeability, thus affecting absorption of numerous, increasingly toxic uremic molecules of low and medium molecular weight, are of particular interest. Finally, although the protein intake prescribed in the present study was exceeded, reaching slightly less than $0.9 \mathrm{~g} / \mathrm{kg} /$ day, after a year one stabilisation period RKF had not deteriorated further in any of the patients studied. These findings therefore may encourage the undertaking of further research in the field using larger patient populations stratified according to age and CKD stage, with the aim of establishing the most appropriate therapeutic strategies for use in restoring optimal metabolic use of AAs and/or rectifying intestinal absorption compromised by a microbiota damaged by the presence of uraemia.

Author Contributions: Conceptualization, methodology, writing-original draft preparation, writing-review and editing, supervision, data curation P.B.; conceptualization, validation, R.A.; software, validation, formal analysis, RM.; investigation, resources M.P.E., M.L.D., M.C., R.S., B.C. and A.S.; methodology, formal analysis P.I. and M.D.; conceptualization, methodology, supervision, data curation, validation, supervision, resources, S.M. All authors have read and agreed to the published version of the manuscript.

Funding: This research received no external funding.

Institutional Review Board Statement: The study was conducted according to the guidelines of the Declaration of Helsinki, and approved by the Ethics Committee of Health Public Institute of Sardinia (ATS) (protocol code MRC Project: 74/2018, approved on 29 May 2018).

Informed Consent Statement: Informed consent was obtained from all subjects involved in the study.

Data Availability Statement: The data presented in this study are available on request from the corresponding author.

\section{References}

1) Tizianello A, De Ferrari G, Garibotto G, Gurreri G, Robaudo C. Renal metabolism of amino acids and ammonia in subjects with normal renal function and in patients with chronic renal insufficiency. J Clin Invest. 1980 May;65(5):1162-73.

2) Tizianello A, Deferrari G, Garibotto G, Robaudo R, Saffioti S, Pontremoli R Amino acid imbalance in patients with chronic renal failure. Contrib Nephrol. 1989;75:185-93.

3) Garibotto G. Muscle amino acid metabolism and the control of muscle protein turnover in patients with chronic renal failure. Nutrition. 1999 Feb;15 (2):145-55.

4) Garibotto G, Sofia A, Saffioti S, Bonanni A, Mannucci I, Verzola D. Amino acid and protein metabolism in the human kidney and in patients with chronic kidney disease .Clin Nutr. 2010 Aug;29(4):424-33.

5) Cupisti A, Brunori G, Di Iorio BR, D'Alessandro C, Pasticci F, Cosola C, Bellizzi V, Bolasco P, Capitanini A, Fantuzzi AL, Gennari A, Piccoli GB, Quintaliani G, Salomone M, Sandrini M, Santoro D, Babini P, Fiaccadori E, Gambaro G, Garibotto G, Gregorini M, Mandreoli M, Minutolo R, Cancarini G, Conte G, Locatelli F, Gesualdo L. Nutritional treatment of advanced CKD: twenty consensus statements. J Nephrol. 2018 Aug;31(4):457-473. 
6) Lee SW, Kim YS, Kim YH, Chung W, Park SK, Choi KH, Ahn C, Oh KH. Dietary Protein Intake, Protein Energy Wasting, and the Progression of Chronic Kidney Disease: Analysis from the KNOW-CKD Study. Nutrients. 2019 Jan 8;11(1).

7) Li F, Wang M, Wang J, Li R, Zhang Y Alterations to the Gut Microbiota and Their Correlation With Inflammatory Factors in Chronic Kidney Disease. Front Cell Infect Microbiol. 2019 Jun 12;9:206.

8) Yang J, Lim SY, Ko YS, Lee HY, Oh SW, Kim MG, Cho WY, Jo SK. Intestinal barrier disruption and dysregulated mucosal immunity contribute to kidney fibrosis in chronic kidney disease. Nephrol Dial Transplant. 2019 Mar 1;34(3):419-428.

9) Rocchetti MT, Di Iorio BR, Vacca M, Cosola C, Marzocco S, di Bari I, Calabrese FM, Ciarcia R, De Angelis M, Gesualdo L . Ketoanalogs' Effects on Intestinal Microbiota Modulation and Uremic Toxins Serum Levels in Chronic Kidney Disease (Medika2 Study). Clin Med. 2021 Feb 18;10(4):840.

10) Hanna, R.M., Ghobry, L., Wassef, O.; Rhee C.M.; Kalantar-Zadeh, K. A Practical Approach to Nutrition, Protein-Energy Wasting, Sarcopenia, and Cachexia in Patients with Chronic Kidney Disease. Blood Purif. 2020, 49, $202-211$.

11) Koppe, L.; Fouque, D.; Kalantar-Zadeh, K. Kidney cachexia or protein-energy wasting in chronic kidney disease: Facts and numbers. J. Cachexia Sarcopenia Muscle 2019, 10, 479-484.

12) Inker LA, Astor BC, Fox CH, Isakova T, Lash JP, Peralta CA, Kurella Tamura M, Feldman HI.KDOQI US commentary on the 2012 KDIGO clinical practice guideline for the evaluation and management of CKD. Am J Kidney Dis. 2014 May;63(5):713-35.

13) De Nicola L, Chiodini P, Zoccali C, Borrelli S, Cianciaruso B, Di Iorio B, Santoro D, Giancaspro V, Abaterusso C, Gallo C, Conte C, Minutolo R, SIN-TABLE CKD Study Group Prognosis of CKD patients receiving outpatient nephrology care in Italy. Clin J Am Soc Nephrol. 2011 Oct;6(10):2421-8.

14) Hommos MS, Glassock RJ, Rule AD. Structural and Functional Changes in Human Kidneys with Healthy Aging. J Am Soc Nephrol; 2017 Oct;28(10):2838-2844.

15) Eriksen BO, Palsson R, Ebert N, Melsom T, van der Giet M, Gudnason V, Indridason OS, Inker LA, Jenssen TG, Levey AS, Solbu MD, Tighiouart H, Schaeffner E. GFR in Healthy Aging: An Individual Participant Data Meta-Analysis of Iohexol Clearance in European Population-Based Cohorts. J Am Soc Nephrol. 2020 Jul;31(7):1602-1615.

16) Kitai Y, Nangaku M, Yanagita M.C. Aging-Related Kidney Diseases. Contrib Nephrol. 2021;199:266-273.

17) Murtas S, Aquilani R, Deiana ML, Iadarola P, Secci R, Cadeddu M, Salis S, Serpi D, Bolasco P. Differences in Amino Acid Loss Between High-Efficiency Hemodialysis and Postdilution and Predilution Hemodiafiltration Using High Convection Volume Exchange-A New Metabolic Scenario? A Pilot Study. J Ren Nutr. 2019 Mar;29(2):126-135.

18) Murtas S, Aquilani R, Iadarola P, Deiana ML, Secci R, Cadeddu M and Bolasco P. Differences and Effects of Metabolic Fate of Individual Amino Acid Loss in High-Efficiency Hemodialysis and Hemodiafiltration. J Ren Nutr. 2020 Sep;30(5):440-451.

19) Bolasco P. Hemodialysis-Nutritional Flaws in Diagnosis and Prescriptions. Could Aminoacid Losses be the Sharpest "Sword of Damocles"? Nutrients. 2020 Jun 14;12(6):1773.

20) Schmidt JA, Rinaldi S, Scalbert A, Ferrari P, Achaintre D, Gunter MJ, Appleby PN, Key TJ, Travis RC. Plasma concentrations and intakes of amino acids in male meat-eaters, fish-eaters, vegetarians and vegans: a cross-sectional analysis in the EPIC-Oxford cohort. Eur J Clin Nutr. 2016 Mar;70(3):306-12.

21) Beasley JM, Firestone MJ, Popp CJ, Russo R, Yi SS Age and Racial/Ethnic Differences in Dietary Sources of Protein, NHANES, 20112016.Front Nutr. 2020 Jun 26; 7:76.

22) Liu X, Hoene M, Wang X, Yin P , Häring H-U , Xu G, Lehmann R. Serum or plasma, what is the difference? Investigations to facilitate the sample material selection decision making process for metabolomics studies and beyond. Anal Chim Acta. 2018 Dec 11; 1037:293-300.

23) Garibotto G, Sofia A, Saffioti S, Bonanni A, Mannucci I, Verzola D. Amino acid and protein metabolism in the human kidney and in patients with chronic kidney disease. Clin Nutr. 2010 Aug;29(4):424-33.

24) Duranton F, Lundin U, Gayrard N, Mischak H, Aparicio M, Mourad G, Daurès J-P, Weinberger KM, Argilés A. Plasma and urinary amino acid metabolomic profiling in patients with different levels of kidney function. Clin J Am Soc Nephrol. . 2014 Jan;9(1):37-45.

25) Roshanravan B, Zelnick LR, Djucovic D, Gu H, Alvarez JA, Ziegler TR, Gamboa JL, Utzschneider K, Kestenbaum B, Himmelfarb J, Kahn SE, Raftery D, de Boer IH. Chronic kidney disease attenuates the plasma metabolome response to insulin. JCI Insight. 2018 Aug 23;3(16): e122219.

26) Foroumandi E, Alizadeh M, Kheirouri S. Age-dependent Changes in Plasma Amino Acids Contribute to Alterations in Glycoxidation Products. J Med Biochem.2018 Dec 1;37(4):426-433.

27) Adey D, Kumar R, McCarthy JT, Nair KS. Reduced synthesis of muscle proteins in chronic renal failure. Am J Physiol Endocrinol Metab. 2000 Feb;278(2): E219-25.

28) Yan B, Su X, Xu B, Qiao X, Wang L. Effect of diet protein restriction on progression of chronic kidney disease: A systematic review and meta-analysis. PLoS One. 2018 Nov 7;13(11): e 0206134.

29) Koppe L, Fouque D, Kalantar-Zadeh K. Kidney cachexia or protein-energy wasting in chronic kidney disease: facts and numbers. J Cachexia Sarcopenia Muscle. 2019 Jun;10(3):479-484.

30) Energy Requirement for Elderly CKD Patients.D'Alessandro C, Giannese D, Avino M, Cupisti A. Nutrients. 2021 Sep 27;13(10):3396.

31) Woolfson AM. Amino acids--their role as an energy source . Proc Nutr Soc. 1983 Sep;42(3):489-95.

32) Cupisti A, Bolasco P. Keto-analogues and essential aminoacids and other supplements in the conservative management of chronic kidney disease. Panminerva Med. 2017 Jun;59(2):149-156.

33) Narasaki Y, Rhee CM, Kramer H, Kalantar-Zadeh K. Protein intake and renal function in older patients. Curr Opin Clin Nutr Metab Care. 2021 Jan;24(1):10-17. 
34) Garibotto G, Bonanni A, Verzola D. Effect of kidney failure and hemodialysis on protein and amino acid metabolism. Curr Opin Clin Nutr Metab Care. 2012 Jan;15(1):78-84.

35) Tan I-K, Gajra B. Plasma and urine amino acid profiles in a healthy adult population of Singapore. Ann Acad Med Singap. 2006 Jul;35(7):468-75.

36) Aquilani R, Maestri R, Dossena M, La Rovere MT, Buonocore D, Boschi F, Verri M. Altered Amino Acid Metabolism in Patients with Cardiorenal Syndrome Type 2: Is It a Problem for Protein and Exercise Prescriptions? Nutrients.2021 May 13;13(5):1632.

37) Liu Y, Li J, Yu J, Wang Y, Lu J, Shang EX, Zhu Z, Guo J, Duan J. Disorder of gut amino acids metabolism during CKD progression is related with gut microbiota dysbiosis and metagenome change. J Pharm Biomed Anal. 2018 Feb 5;149:425-435.

38) The Gut as a Source of Inflammation in Chronic Kidney Disease. Lau WL, Kalantar-Zadeh K, Vaziri ND. Nephron. 2015;130(2):92-8.

39) Vaziri ND, Zhao YY, Pahl MV Altered intestinal microbial flora and impaired epithelial barrier structure and function in CKD: the nature, mechanisms, consequences and potential treatment. Nephrol Dial Transplant. 2016 May;31(5):737-46.

40) Graboski AL, Redinbo MR. Gut-Derived Protein-Bound Uremic Toxins. Toxins (Basel). 2020 Sep 11;12(9):590.

41) Steenbeke M, Valkenburg S, Gryp T, Van Biesen W, Delanghe JR, Speeckaert MM, Glorieux G. Gut Microbiota and Their Derived Metabolites, a Search for Potential Targets to Limit Accumulation of Protein-Bound Uremic Toxins in Chronic Kidney Disease.Toxins (Basel). 2021 Nov 17;13(11):809.

42) Gryp T, Vanholder R, Vaneechoutte M, Glorieux G.p-Cresyl Sulfate. Toxins (Basel). 2017 Jan 29;9(2):52.

43) Gryp T, De Paepe K, Vanholder R, Kerckhof FM, Van Biesen W, Van de Wiele T, Verbeke F, Speeckaert M, Joossens M, Couttenye MM, Vaneechoutte M, Glorieux G. Gut microbiota generation of protein-bound uremic toxins and related metabolites is not altered at different stages of chronic kidney disease. Kidney Int. 2020 Jun;97(6):1230-1242.

44) Xu Y, Wang Y, Li H, Dai Y, Chen D, Wang M, Jiang X, Huang Z, Yu H, Huang J, Xiong Z Altered Fecal Microbiota Composition in Older Adults With Frailty. Front Cell Infect Microbiol. 2021 Aug 17;11: 696186.

45) Wegh CAM, de Roos NM, Hovenier R, Meijerink J, Besseling-van der Vaart I, van Hemert S, Witteman Intestinal Permeability Measured by Urinary Sucrose Excretion Correlates with Serum Zonulin and Faecal Calprotectin Concentrations in UC Patients in Remission. BJM. J Nutr Metab. 2019 Apr 1; 2019:2472754.

46) Astudillo-López CC, Castro-Alarcón N, Ariza AC, Muñoz-Valle JF, de la Cruz-Mosso U, Flores-Alfaro E, del Moral-Hernández Oscar, Moreno-Godínez ME, Ramírez-Vargas MA, Matia-Garcia I and Parra-Rojas I. Influence of Diet and Levels of Zonulin, Lipopolysaccharide and C-Reactive Protein on Cardiometabolic Risk Factors in Young Subjects. Nutrients 2021, 13(12), 4472;

47) de Kort, S, Keszthelyi, D, Masclee A.A.M, Leaky gut and diabetes mellitus: What is the link? Obes. Rev. 2011, 12, 449-458.

48) Ayling RM, Kok K. Fecal Calprotectin. Adv Clin Chem. 2018; 87:161-190.

49) Ricciuto A, Griffiths AM. Clinical Value of fecal calprotectin. Crit Rev Clin Lab Sci. 2019 Aug;56(5):307-320.

50) Bryce C, Bucaj M. Fecal Calprotectin for the Evaluation of Inflammatory Bowel Disease.

Am Fam Physician. 2021 Sep 1;104(3):303-304.

51) Jukic A, Bakiri L, Wagner EF, Tilg H, Adolph Calprotectin: from biomarker to biological function. TE.Gut. 2021 Oct;70(10):1978-1988.

52) Maroni BJ, Steinman TI, Mitch WE A method for estimating nitrogen intake of patients with chronic renal failure. Kidney Int. 1985 Jan;27(1):58-65.

53) Masud T, Manatunga A, Cotsonis G, Mitch WE The precision of estimating protein intake of patients with chronic renal failure. Kidney Int. 2002 Nov;62(5):1750-6.

54) K/DOQI clinical practice guidelines for chronic kidney disease: evaluation, classification, and stratification. Am J Kidney Dis. 2002 Feb;39(2 Suppl 1): S1-266.

55) Lubowitz H, Slatopolsky E, Shankel S, Rieselbach RE, Bricker NS. Glomerular Filtration Rate Determination in Patients With Chronic Renal Disease JAMA. 1967;199(4):252-256.

56) Diana C Grootendorst, Wieneke M Michels, Jermaine D Richardson, Kitty J Jager, Elisabeth W Boeschoten, Friedo W Dekker, Raymond T Krediet. NECOSAD Study Group The MDRD formula does not reflect GFR in ESRD patients. Nephrol Dial Transplant 2011 Jun;26(6):1932-7.

57) Bolasco P, Casula L, Contu R, Cadeddu M, Murtas S Evaluation of Residual Kidney Function during Once-Weekly Incremental Hemodialysis. Blood Purif. 2021;50(2):246-253.

58) Levey AS, Inker LA, Coresh J. GFR estimation: from physiology to public health. Am J Kidney Dis. 2014 May;63(5):820-34.

59) Almutary H, Bonner A, Douglas C Symptom burden in chronic kidney disease: a review of recent literature. J Ren Care. 2013 Sep;39(3):140-50.

60) Cupisti A, D'Alessandro C, Fumagalli G, Vigo V, Meola M, Cianchi C, Egidi MF. Nutrition and physical activity in CKD patients. Kidney Blood Press Res. 2014;39(2-3):107-13.

61) Wang WL, Liang S, Zhu FL, Liu JQ, Chen XM, Cai GY Association of the malnutrition-inflammation score with anthropometry and body composition measurements in patients with chronic kidney disease. Ann Palliat Med. 2019 Nov;8(5):596-603.

62) Fouque D, Chen J, Chen W, Garneata L, Hwang SJ, Kalantar-Zadeh K, Kopple JD, Mitch WE, Piccoli G, Teplan V, Chauveau P. Adherence to ketoacids/essential amino acids-supplemented low protein diets and new indications for patients with chronic kidney disease. BMC Nephrol. 2016 Jul 7;17(1):63.

63) Rizzetto F, de Oliveira Leal V, Bastos LS, Fouque D, Denise Mafra D. Chronic kidney disease progression: a retrospective analysis of 3-year adherence to a low protein diet. Ren Fail. 2017 Nov;39(1):357-362.

64) Rhee CM, Ahmadi SF, Kovesdy CP, Kalantar-Zadeh K Low-protein diet for conservative management of chronic kidney disease: a systematic review and meta-analysis of controlled trials. J Cachexia Sarcopenia Muscle. 2018 Apr;9(2):235-245. 
65) Cupisti A, Gallieni M, Avesani CM, D'Alessandro C, Carrero JJ, Piccoli GB. Medical Nutritional Therapy for Patients with Chronic Kidney Disease not on Dialysis: The Low Protein Diet as a Medication. J Clin Med. 2020 Nov 12;9(11):3644.

66) Apetrii M, Timofte D, Voroneanu L, Covic A. Nutrition in Chronic Kidney Disease-The Role of Proteins and Specific Diets. Nutrients. 2021 Mar 16;13(3):956

67) Kaesler N, Baid-Agrawal S, Grams S, Nadal J, Schmid M, Schneider MP, Eckardt KU, Floege J, Bergmann MM, Schlieper G, Saritas T. Low adherence to CKD-specific dietary recommendations associates with impaired kidney function, dyslipidemia, and inflammation. Eur J Clin Nutr. 2021 Sep;75(9):1389-1397.

68) Notaras S, Conti J. A qualitative analysis of eating behavior changes for patients with diabetes and non-dialysis dependent chronic kidney disease stages 4-5. J Ren Care. 2018 Dec;44(4):219-228.

69) Pottel H, Hoste L, Dubourg L, Ebert N, Schaeffner E, Eriksen BO, Melsom T, Lamb EJ, Rule AD, Turner ST, Glassock RJ, De Souza V, Selistre L, Mariat C, Martens F, Delanaye P. An estimated glomerular filtration rate equation for the full age spectrum. Nephrol Dial Transplant. 2016 May;31(5):798-806.

70) Cohen C. Molecular mechanisms of renal aging]. Nephrol Ther. 2021 Apr; 17S:S108-S114.

71) Santin Y, Lluel P, Rischmann P, Gamé X, Mialet-Perez J, Parini A. Cellular Senescence in Renal and Urinary Tract Disorders. Cells. 2020 Nov 5;9(11):2420.

72) Garibotto, G.; Sofia, A.; Russo, R.; Paoletti, E.; Bonanni, A.; Parodi, E.L.; Viazzi, F.; Verzola, D. Insulin sensitivity of muscle protein metabolism is altered in patients with chronic kidney disease and metabolic acidosis. Kidney Int. 2015, 88, 1419-1426.

73) Rasmussen BB, Fujita S, Wolfe R et al. Insulin resistance of muscle protein metabolism in aging. Diabetologia 2009; 52: 1889-1898.

74) Wang F, Sun L, Sun Q, Liang L, Gao X, Li R, Pan A, Li H, Deng Y, Hu FB, Wu J, Zeng R, Xu L .Associations of Plasma Amino Acid and Acylcarnitine Profiles with Incident Reduced Glomerular Filtration Rate. Clin J Am Soc Nephrol. 2018 Apr 6;13(4):560-568.

75) Mahbub MH, Yamaguchi N, Nakagami Y, Hase R, Takahashi H, Ishimaru Y, Watanabe R, Saito H, Shimokawa J, Yamamoto H, Kikuchi S, Tanabe T. Association of Plasma Branched-Chain and Aromatic Amino Acids with Reduction in Kidney Function Evaluated in Apparently Healthy Adults. J Clin Med. 2021 Nov 10;10(22):5234.

76) Kumar, M.A.; Bitla, A.R.; Raju, K.V.; Manohar, S.M.; Kumar, V.S.; Narasimha, S.R. Branched chain amino acid profile in early chronic kidney disease. Saudi J. Kidney Dis. Transpl. 2012, 23, 1202-1207.

77) Li, Y.; Tang, A.G.; Mu, S. HPLC-FLD determination of serum aromatic amino acids: Application in chronic kidney disease patients. Clin. Chim. Acta 2011, 412, 1032-1035.

78) Suliman, M.E.; Qureshi, A.R.; Stenvinkel, P.; Pecoits-Filho, R.; Bárány, P.; Heimbu“rger, O.; Anderstam, B.; Rodríguez Ayala, E.; Divino Filho, J.C.; Alvestrand, A. Inflammation contributes to low plasma amino acid concentrations in patients with chronic kidney disease. Am. J. Clin. Nutr. 2005, 82, 342-349.

79) Young, G.A.; Swanepoel, C.R.; Croft, M.R.; Hobson, S.M.; Parsons, F.M. Anthropometry and plasma valine, amino acids, and proteins in the nutritional assessment of hemodialysis patients. Kidney Int. 1982, 21, 492-499.

80) Ceballos, I.; Chauveau, P.; Guerin, V.; Bardet, J.; Parvy, P.; Kamoun, P.; Jungers, P. Early alterations of plasma free amino acids in chronic renal failure. Clin. Chim. Acta 1990, 188, 101-108.

81) Laidlaw SA, Berg RL, Kopple JD, Naito H, Walker WG, Walser M. Patterns of fasting plasma amino acid levels in chronic renal insufficiency: results from the feasibility phase of the Modification of Diet in Renal Disease Study. Am J Kidney Dis 1994 Apr;23(4):504-13.

82) Laidlaw SA, Berg RL, Kopple JD, Naito H, Walker WG, Walser M. Early alterations of plasma free amino acids in chronic renal failure. Am J Kidney Dis. 1994 Apr;23(4):504-13.

83) Ceballos I, Chauveau P, Guerin V, Bardet J, Parvy P, Kamoun P, Junger. Early alterations of plasma free amino acids in chronic renal failure. Clin Chim Acta. 1990 Apr 30;188(2):101-8.

84) Rodrigues SD, Batista GB, Ingberman M, Pecoits-Filho R, Nakao LS. Plasma cysteine/cystine reduction potential correlates with plasma creatinine levels in chronic kidney disease. Blood Purif. 2012;34(3-4):231-7.

85) Mitch WE, Price SR, May RC, Jurkovitz C, England BK. Metabolic consequences of uremia: extending the concept of adaptive responses to protein metabolism. Am J Kidney Dis. 1994 Feb;23(2):224-8.

86) Mair RD, Lee S, Plummer NS, Sirich TL, Meyer TW. Impaired Tubular Secretion of Organic Solutes in Advanced Chronic Kidney Disease. J Am Soc Nephrol. 2021 Nov;32(11):2877-2884.

87) Carr SJ, Layward E, Bevington A, Hattersley J, Walls J. Plasma amino acid profile in the elderly with increasing uraemia. Nephron. 1994;66(2):228-30.

88) Calabrò RS, Gervasi G, Bramanti P. L-Arginine and vascular diseases: lights and pitfalls! Acta Biomed. 2014 Dec 17;85(3):222-8.

89) Konje VC, Rajendiran TM, Bellovich K, Gadegbeku CA, Gipson DS, Afshinnia F, Mathew AV; Tryptophan levels associate with incident cardiovascular disease in chronic kidney Disease. Michigan Kidney Translational Core CPROBE Investigator Group.Clin Kidney J. 2020 Apr 12;14(4):1097-1105.

90) Piccoli GB, Di Iorio BR, Chatrenet A, D'Alessandro C, Nazha M, Capizzi I, Vigotti FN, Fois A, Maxia S, Saulnier P, Cabiddu G, Cupisti A Dietary satisfaction and quality of life in chronic kidney disease patients on low-protein diets: a multicentre study with long-term outcome data (Torino-Pisa study). Nephrol Dial Transplant. 2020 May 1;35(5):790-802.

91) Bellizzi V, Signoriello S, Minutolo R, Di Iorio B, Nazzaro P, Garofalo C, Calella P, Chiodini P, De Nicola L; ERIKA Study Investigators of the Italian Society of Nephrology-Conservative Therapy of CKD Work Group. No additional benefit of prescribing a very lowprotein diet in patients with advanced Chronic Kidney Disease under regular nephrology care: a pragmatic, randomized, controlled trial. Am J Clin Nutr. 2021 Dec 30: nqab417. 